\title{
Congenital agenesis of internal carotid artery with ipsilateral Horner presenting as focal neurological symptoms
}

This article was published in the following Dove Press journal:

Vascular Health and Risk Management

25 January $201 \mathrm{I}$

Number of times this article has been viewed

\section{Wassim Farhat \\ Rechdi Ahdab \\ Hassan Hosseini}

Service de Neurologie, Hôpital Henri Mondor, APHP, Faculté de Médecine, Université Paris XII, Créteil, France
Correspondence: Hassan Hosseini Service de Neurologie, Hôpital Henri Mondor, 5I Avenue de Lattre de Tassigny, 94010 Créteil CEDEX, France Email hassan.hosseini@hmn.aphp.fr

\begin{abstract}
Internal carotid artery (ICA) agenesis is a rare developmental anomaly and is most frequently asymptomatic, but it may also present as cerebrovascular accidents. The association with Horner's syndrome is exceptional. We present three cases of agenesis of ICA associated with Horner's syndrome and hypochromia iridum presenting as focal neurological symptoms. A system of collaterals develops as a consequence of agenesis of the ICA, making the majority of cases asymptomatic. Three types of collateral circulations have been described. These collaterals increase the risk of aneurysm formation and the occurrence of life-threatening subarachnoid hemorrhages. The association of congenital Horner's syndrome and hypochromia iridum without anhidrosis is highly suggestive of sympathetic pathway injury early in life. Such signs should prompt further diagnostic evaluation to demonstrate the presence of the agenesis of the carotid canal. Early diagnosis is essential to rule out potentially life-threatening associated vascular anomalies.
\end{abstract}

Keywords: carotid artery agenesis, Horner's syndrome, heterochromia iridum

\section{Introduction}

Developmental anomalies of internal carotid artery (ICA), agenesis/hypoplasia, are rare, and etiologies are not well known. Most frequently, they are asymptomatic due to collateral formations, but they may also present as cerebrovascular accidents (CVA) (ischemic and hemorrhagic). The association with Horner's syndrome is exceptional. We present three cases of agenesis of ICA with Horner's syndrome presenting as focal neurological symptoms.

\section{Case report I}

A 22-year-old man presented, 2 weeks after a neck trauma, for numbness and motor deficit of the three first fingers of the left hand. Two days later, the symptoms progressed more proximally and reached the left side of the face. Upon examination, a left-sided miosis and blepharoptosis was noticed along with left iris discoloration (Figure 1A), but the patient stated that those had been present since birth, and old photos confirmed his statement. No ipsilateral anhidrosis or flushing was noted. Brain magnetic resonance imaging (MRI) with magnetic resonance angiography (MRA) showed ischemic lesion at the right knob area, absence of the left ICA, dissection of the right ICA, anterior communicating artery supplying the left anterior cerebral artery (ACA), and left posterior communicating artery supplying the left middle cerebral artery (MCA) (Figure 2A). Computed tomography (CT) scan of the skull base showed hypoplasia of the left carotid canal (Figure 3A). The final diagnosis was right internal carotid 


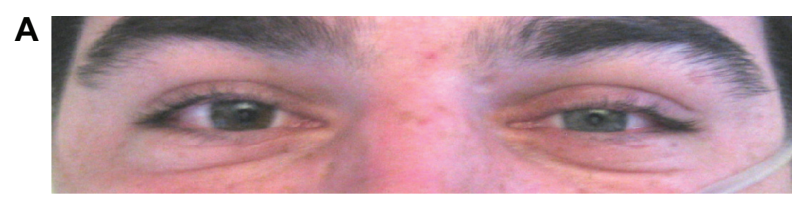

B

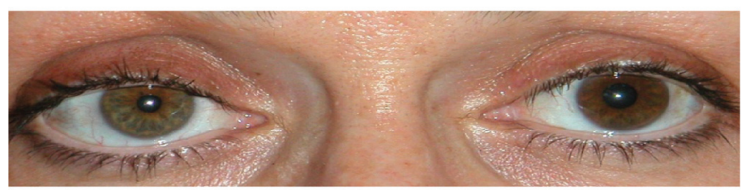

C

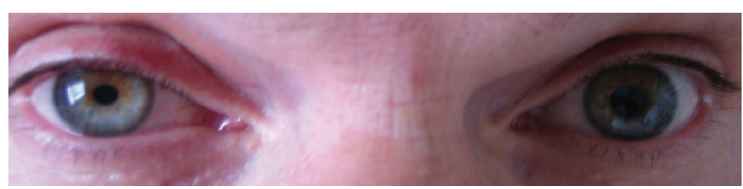

Figure I Photographs of the patients showing miosis, ptosis, and heterochromia iridum (A, left eye; B, C, right eye).

post-traumatic dissection with left ICA congenital agenesis associated with left congenital Horner's syndrome.

\section{Case report 2}

A 43-year-old woman with negative past medical history presented with paresthesias of the left upper limb of progressive onset for several days. She denied motor weakness, headache, neck trauma, or cervical pain. The physical exam was pertinent for low blood pressure $(80 / 40 \mathrm{~mm} \mathrm{Hg})$, right carotid murmur, and left Babinski sign. In addition, right miosis, ptosis, and iris heterochromia were noted (Figure 1B). However, these had been present since birth as confirmed by old photos.

The patient did not suffer from right facial anhidrosis. Brain MRI was normal; neck MRA showed a small right common carotid caliber, stenosis of the right internal carotid artery for a length of $20 \mathrm{~mm}$ without intramural hematoma, and multiple transcranial anastomosis with the right external carotid artery (Figure 2B). CT scan of the skull base showed a hypoplastic right carotid canal (Figure 3B). Poor pupil dilatation to cocaine test confirmed right Horner's syndrome. Final diagnosis was a right congenital Horner's syndrome with right ICA agenesis.

\section{Case report 3}

A 38-year-old man, without cardiovascular risk factors, presented for two episodes of left brachiofacial paresis of acute onset, lasting each time less than an hour. Physical exam showed right-sided ptosis, myosis, and iris hypochromia (Figure 1C). The patient stated that these signs had been present since birth as confirmed by old photos. Brain MRI was normal but carotid angioscan showed agenesis of
A

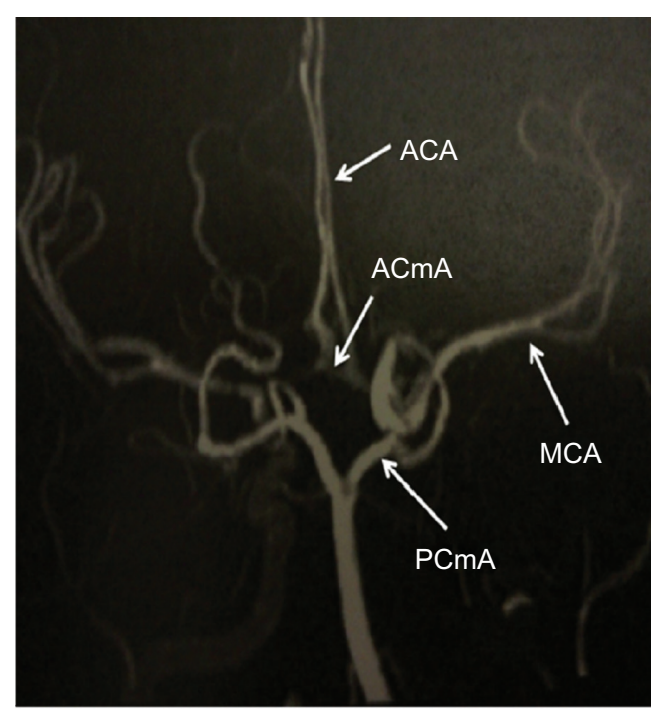

B

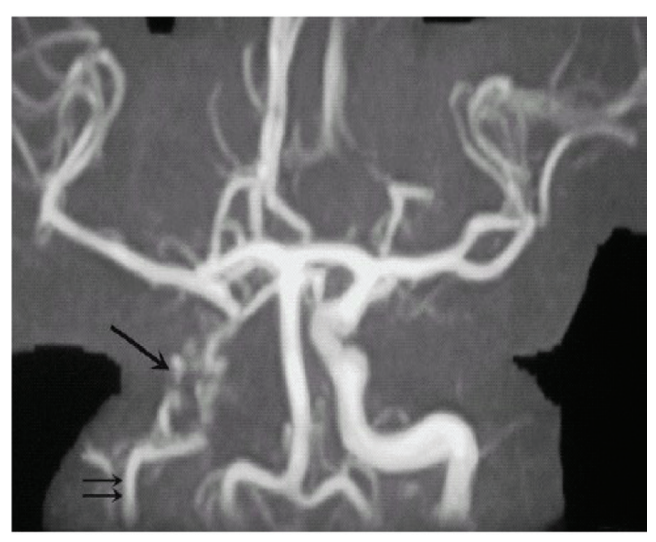

C

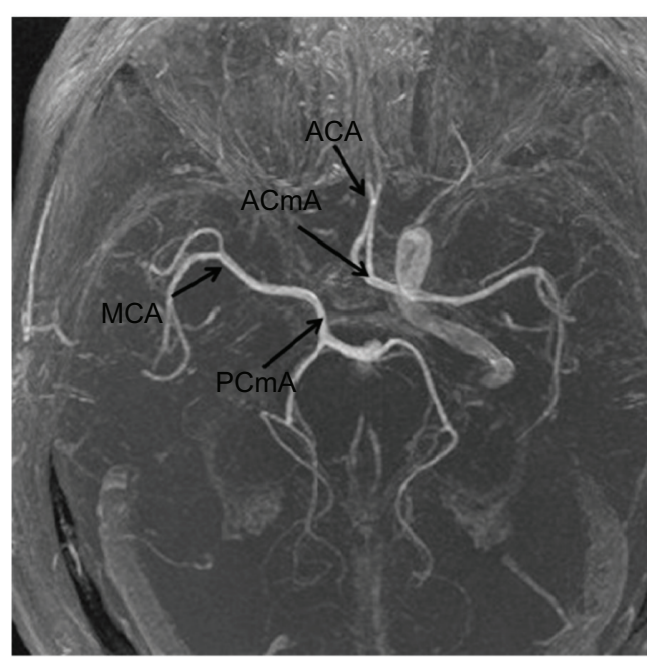

Figure 2 A) MRA showing the circle of Willis with the absence of the left ICA, and dissection of the right ICA, ACmA supplying the left ACA, and left PCmA supplying the left MCA. B) MRA showing the circle of Willis with absence of right ICA and the multiple transcranial anastomosis with the right external carotid artery. C) CTA showing the circle of Willis with absence of right ICA with the anterior communicating artery supplying the right anterior cerebral artery and the right posterior communicating artery supplying the right middle cerebral artery.

Abbreviations: MRA, magnetic resonance angiography; ICA, internal carotid artery; ACA, anterior cerebral artery; MCA, middle cerebral artery; CTA, computed tomography angiography; $\mathrm{ACmA}$, anterior communicating artery; $\mathrm{PCmA}$, posterior communicating artery. 
A

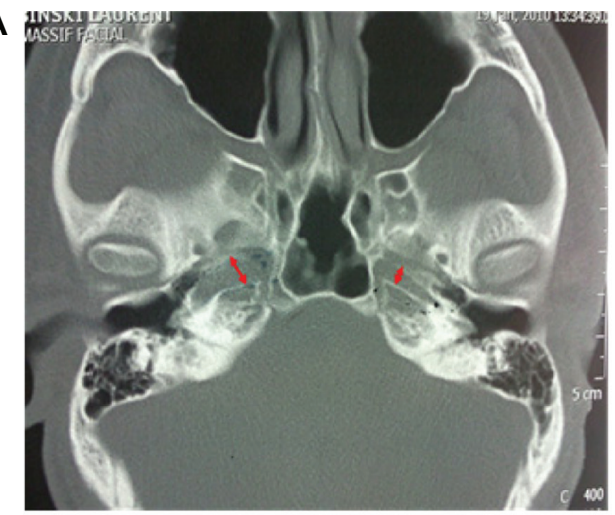

B

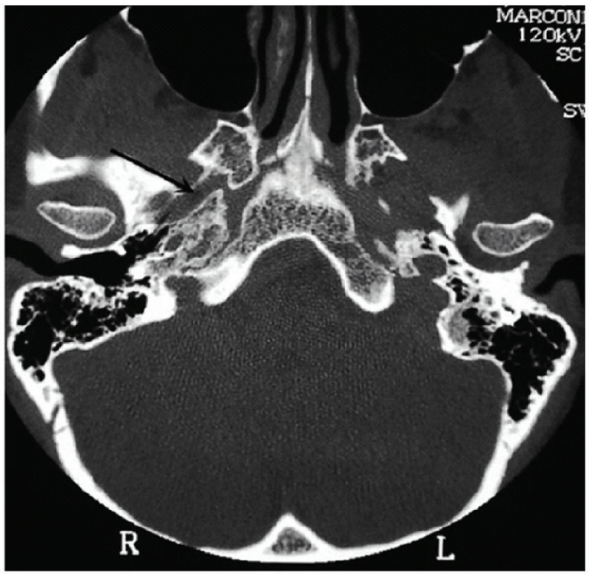

C

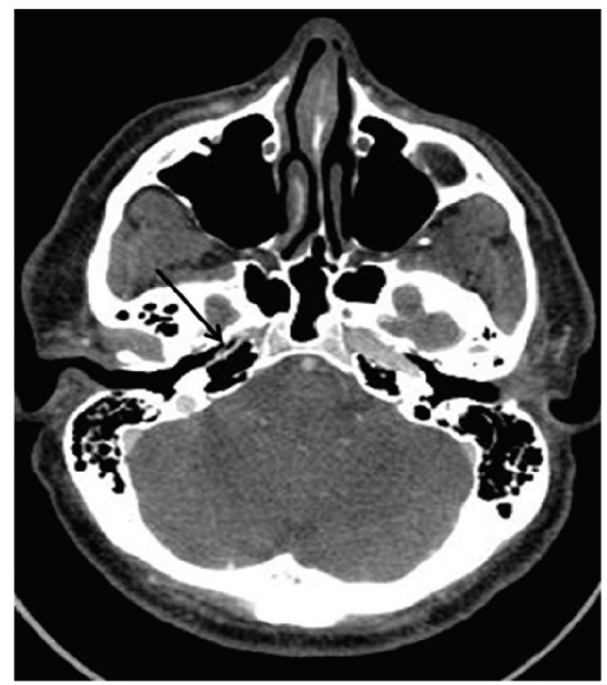

Figure $3 \mathrm{CT}$ scan of the base of the skull showing hypoplastic carotid canal at A) left and at $\mathbf{B}, \mathbf{C})$ right.

$\mathrm{A}=$ case $\mathrm{I}, \mathrm{B}=$ case $2, \mathrm{C}=$ case 3

Abbreviation: $\mathrm{CT}$, computed tomography.

the right ICA, anterior communicating artery supplying the right $\mathrm{ACA}$, and the right posterior communicating artery supplying the right MCA (Figure 2C). Base of skull CT scan showed hypoplasia of the right carotid canal (Figure 3C). Final diagnosis was a right ICA congenital agenesis with ipsilateral Horner's syndrome.

\section{Discussion}

We present three cases of congenital ICA agenesis that presented with cerebrovascular accidents. The three patients had ipsilateral Horner's syndrome with hypochromia iridum present since birth, in addition to hypoplasia or absence of the carotid canal.

The incidence of congenital ICA agenesis is very rare and was reported by Dinç et al to be $<0.5 \% .^{1}$ The ICA develops from the terminal segment of the dorsal aorta and the third aortic arch arteries before the embryologic stage of $3 \mathrm{~mm}$ (24 days). The skull base starts to develop around the fifth week of gestation. If the ICA is absent, the carotid canal fails to develop..$^{2-4}$ So CT scan of the skull base showing a hypoplastic or absent carotid canal differentiates congenital absence of the ICA from other causes of stenosis-like dissection, atherosclerosis, or fibromuscular dysplasia.

A system of collaterals develops as a consequence of agenesis of the ICA, making the majority of cases asymptomatic. Three types of collateral circulations have been described. The fetal type, where the anterior communicating artery supplies the ACA and the posterior communicating artery supplies the MCA, is the most common. The adult type, where the anterior communicating artery supplies both ACA and MCA, is the next most common. And finally, the rarest type or type $\mathrm{F}$ of $\mathrm{Lie}^{5}$ is where transcranial anastomosis from the external carotid, contralateral ICA, or primitive vessels supply the brain., ${ }^{2,5-7}$ Our first and third cases had the first type, whereas the second case had the third type.

These collaterals do not prevent completely the occurrence of TIAs or even CVAs. In addition, they increase the risk of aneurysm formation and the occurrence of subarachnoid hemorrhage.

Other conditions may be associated, such as agenesis of corpus callosum, meningocele, neurofibromatosis, KlippelFeil syndrome, 22q11.2 deletion syndrome, coarctation of the aorta, and other cardiac anomalies. ${ }^{8-11}$

Horner's syndrome results from the interruption of the sympathetic innervations of the pupillary dilator and the Muller's muscle. Congenital Horner's syndrome is rare and may be due to delivery trauma, congenital viral infections (varicella and cytomegalovirus), and compression by ganglioneuroma or cervical lymph node. .,12,13 $^{-13}$

The coexistence of congenital Horner's syndrome and agenesis of the ICA is exceptional and is reported in around 10 cases in the literature. ${ }^{1,4,14,15}$ One possible explanation of this unusual association is the interruption of the ocular sympathetic nerve along the ICA and its incapacity to gain 
access to the cranium in the absence of this artery during embryogenesis. ${ }^{15}$

Iris melanocytes are under sympathetic control, and iris pigmentation is completed by the age of 2 years. Absence of oculosympathetic stimulation decreases the production of melanin. As such, a hypopigmented iris indicates an oculosympathetic pathway injury early in life..$^{15,16}$

The absence of anhidrosis, which was present in our three patients, may be explained by the fact that the sympathetic pathway to the facial sweat glands follows the external carotid artery, ${ }^{17}$ proving that the interruption of the ICA was distal to the common carotid artery bifurcation.

In conclusion, the association of congenital Horner's syndrome and hypochromia iridum without anhidrosis are highly suggestive of sympathetic pathway injury early in life. Such signs should prompt further diagnostic evaluation to demonstrate the presence of hypoplasia of the carotid canal. Despite the fact that agenesis of the ICA is a congenital anomaly that has no cure, finding this anomaly should prompt further studies to detect any associated aneurysm, which if found and treated before rupture, could be lifesaving and can prevent catastrophic neurological complications.

\section{Disclosure}

The authors report no conflicts of interest. They disclose no financial or material support for this work.

\section{References}

1. Dinç H, Alioglu Z, Erdöl H, Ahmetoglu A. Agenesis of the internal carotid artery associated with aortic arch anomaly in a patient with congenital Horner's syndrome. AJNR Am J Neuroradiol. 2002;23(6): 929-931.

2. Damry N, Hanquinet S, Christophe C, Janssen F, Delatte P, Perlmutter N. Bilateral congenital absence of the internal carotid artery with a primitive transmaxillary arterial anastomosis. Pediatr Radiol. 1994; 24(3):200-203.
3. Florio F, Balzano S, Nardella M, et al. Congenital absence of the internal carotid artery. Cardiovasc Intervent Radiol. 1999;22(1):74-78.

4. Ryan FH, Kline LB, Gomez C. Congenital Horner's syndrome resulting from agenesis of the internal carotid artery. Ophthalmology. 2000; 107(1):185-188.

5. Lie TA. Congenital anomalies of the carotid arteries. Excerpta Medica, Amsterdam, 1968; 44-49.

6. Midkiff RB, Boykin MW, McFarland DR, Bauman JA. Agenesis of the internal carotid artery with intercavernous anastomosis. AJNR Am J Neuroradiol. 1995;16(6):1356-1359.

7. Cali RL, Berg R, Rama K. Bilateral internal carotid artery agenesis: a case study and review of the literature. Surgery. 1993;113(2):227-233.

8. Smith RR, Kees CJ, Hogg ID. Agenesis of the internal carotid artery with an unusual primitive collateral. Case report. J Neurosurg. 1972;37(4): 460-462.

9. Chen MC, Liu HM, Huang KM. Agenesis of the internal carotid artery associated with neurofibromatosis type II. AJNR Am J Neuroradiol. 1994;15(6):1184-1186.

10. Braga M, Pederzoli M, Beretta $\mathrm{S}$, et al. Agenesis of the right internal carotid artery and Klippel-Feil syndrome: case report. Spine (Phila Pa 1976). 2009;34(20):E740-E742.

11. Johnson MD, Gentry LR, Rice GM, Mount DL. A case of congenitally absent left internal carotid artery: vascular malformations in 22q11.2 deletion syndrome. Cleft Palate Craniofac J. 2010;47(3):314-317.

12. Hills J, Sament S. Bilateral agenesis of the internal carotid artery associated with cardiac and other anomalies. Case report. Neurology. 1968;18(2):142-146.

13. Leung AK. Congenital Horner's syndrome. Ala J Med Sci. 1986;23(2): 204-205.

14. Hageman G, Ippel PF, te Nijenhuis FC. Autosomal dominant congenital Horner's syndrome in a Dutch family. J Neurol Neurosurg Psychiatry. 1992;55(1):28-30.

15. Tubbs RS, Oakes WJ. Horner's syndrome resulting from agenesis of the internal carotid artery: report of a third case. Childs Nerv Syst. 2005; 21(1):81-82.

16. Fons C, Vasconcelos M, Vidal M, et al. Agenesis of internal carotid artery in a child with ipsilateral Horner's syndrome. J Child Neurol. 2009;24(1):101-104.

17. Odin L, O’Donnell FE Jr. Adrenergic influence on iris stromal pigmentation: evidence for alpha-adrenergic receptors. Invest Ophthalmol Vis Sci. 1982;23(4):528-530.

18. Masdeu JC, Brazis PW. The localisation of lesions in the ocular motor system. In: Brazis PW, Masdeu JC, Biller J, editors. Localisation in Clinical Neurology. 2nd ed. Boston: Little, Brown and Company; 1990: 127-188.
Vascular Health and Risk Management

\section{Publish your work in this journal}

Vascular Health and Risk Management is an international, peerreviewed journal of therapeutics and risk management, focusing on concise rapid reporting of clinical studies on the processes involved in the maintenance of vascular health; the monitoring, prevention and treatment of vascular disease and its sequelae; and the involvement of

\section{Dovepress}

metabolic disorders, particularly diabetes. This journal is indexed on PubMed Central and MedLine. The manuscript management system is completely online and includes a very quick and fair peer-review system, which is all easy to use. Visit http://www.dovepress.com/ testimonials.php to read real quotes from published authors. 